\title{
Adaptation of a difficult airway trolley in a low resource setting
}

\author{
Nimangee Wathsala Mithraratne ${ }^{1^{*}}$, Sita Alwis ${ }^{2}$, Lakshmi Ranasinghe ${ }^{2}$ \\ Registrar in Anaesthesiology ${ }^{1^{*}}$, Consultant Anaesthetist ${ }^{2}$, \\ Colombo South Teaching Hospital, Sri Lanka
}

Keywords: Difficult airway trolley; difficult airway guidelines; quality improvement

Editor,

Complications of a difficult airway although infrequent can be quite detrimental leading to severe morbidity and mortality during intubation. ${ }^{1}$ The NAP4 study estimated that 1 in every 22000 airways had a serious complication during general anaesthesia, with 1 in 150000 resulting in brain damage or even death. ${ }^{1}$

The difficult airway trolley (DAT) is an essential component in an area where a patient's airway is managed, such as an operation theatre (OT) or an intensive care unit. Although most of the components described in a DAT are easily and readily found in areas mentioned above, the importance of a logically and comprehensively stocked DAT that follows some conformity to a given institution cannot be emphasized enough. It avoids delays, misunderstanding and in an emergency, every anaesthetist will be familiar with the use of its contents and the sequence one must adhere to.

\section{Problems identified}

The main operating theatre at Colombo South Teaching Hospital Sri Lanka, is a fully equipped OT complex handling the daily casualty burden of the 1093 bedded hospital -the second largest hospital in Colombo. There are numerous casualty surgeries that take place in this theatre complex which also handles a significant amount of trauma and emergency surgeries sometimes done under the distant supervision of consultants.

Here, it is not rare to encounter the occasional anticipated and unanticipated difficult airway during the day. We were able to identify a significant deficiency of not having an organized
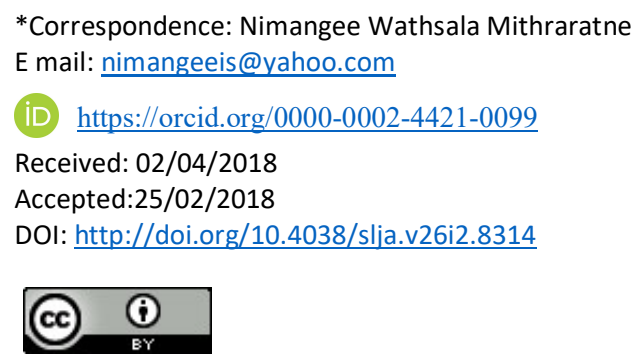

airway trolley in such a busy unit where help may not always be readily available, especially during the nights.

Here is a suggested DAT with equipment based on the Difficult Airway Society guidelines laid down in $2015 .^{2}$

\begin{tabular}{|c|c|}
\hline Optimize head position & $\begin{array}{l}\text { Contents } \\
\text { Bougie } \\
\text { Alternative laryngoscopes } \\
\text { Short handle laryngoscope } \\
\text { McCoy blade and/or straight blade } \\
\text { Videolaryngoscope }\end{array}$ \\
\hline $\begin{array}{l}\text { Drawer } 2 \\
\text { Plan B } \\
\text { LMA - Followed by } \\
\text { fibreoptic tracheal } \\
\text { intubation through LMA }\end{array}$ & $\begin{array}{l}\text { Contents } \\
\text { LMA \#3,4,5 \&/or } 2^{\text {nd }} \text { generation } \\
\text { device, } \# 3,4,5 \\
\text { Intubating LMA (iLMA) } \# 3,4,5 \\
\text { Aintree Intubating Catheter (ideally on } \\
\text { side of trolley) } \\
\text { Fibreoptic adjuvants }\end{array}$ \\
\hline $\begin{array}{l}\text { Drawer } 3 \\
\text { Plan C } \\
\text { Bag mask ventilation }+/- \\
\text { airway adjuncts } \\
\text { Supraglottic airway } \\
\text { device }\end{array}$ & $\begin{array}{l}\text { Contents } \\
\text { Facemasks - various sizes } \\
\text { Oropharyngeal airways - various sizes } \\
\text { Nasopharyngeal airways - various } \\
\text { sizes } \\
\text { LMA/Proseal LMA - \#3,4,5 }\end{array}$ \\
\hline $\begin{array}{l}\text { Drawer } 4 \\
\text { Plan D } \\
\text { Surgical } \\
\text { cricothyroidotomy }\end{array}$ & $\begin{array}{l}\text { Contents } \\
\text { Large bore cannula device eg. } \\
\text { Quicktrach I or II (VBM) } \\
\text { Scalpel (No. } 20 \text { blade) } \\
\text { Tracheal dilator or tracheal hook } \\
\text { Bougie } \\
\text { Cuffed tracheal tube \#6 \& } 7\end{array}$ \\
\hline Miscellaneous & $\begin{array}{l}\text { DAS intubation guidelines (laminated) } \\
\text { or locally agreed algorithms } \\
\text { Equipment checklist for re-stocking } \\
\text { Logbook for daily checking } \\
\text { procedures } \\
\text { Specific extubation aids/equipment eg. } \\
\text { Staged Extubation Set (Cook Medical) } \\
\text { Extubation guidelines (laminated) }\end{array}$ \\
\hline
\end{tabular}

Table 1: Composition of DAT

Goals

Our objective was to design a DAT that follows all conforms of the most recent DAS 2015 guideline, yet which is practical for the use in our local setup. This needed to be robust, cheap and locally sourced, compact and transportable to be used in each of the 4 theatres in the complex. 
It needed to be stocked with all necessary airway equipment without over stocking and be readily accessible in an emergency.

Apart from the laminated guidelines hanging from the corner of the trolley we also wanted to use a visual prompt-a sticker depicting the progression of each of the DAS guideline steps from A to D.

\section{Design}

This was the finished product with the relevant contents.
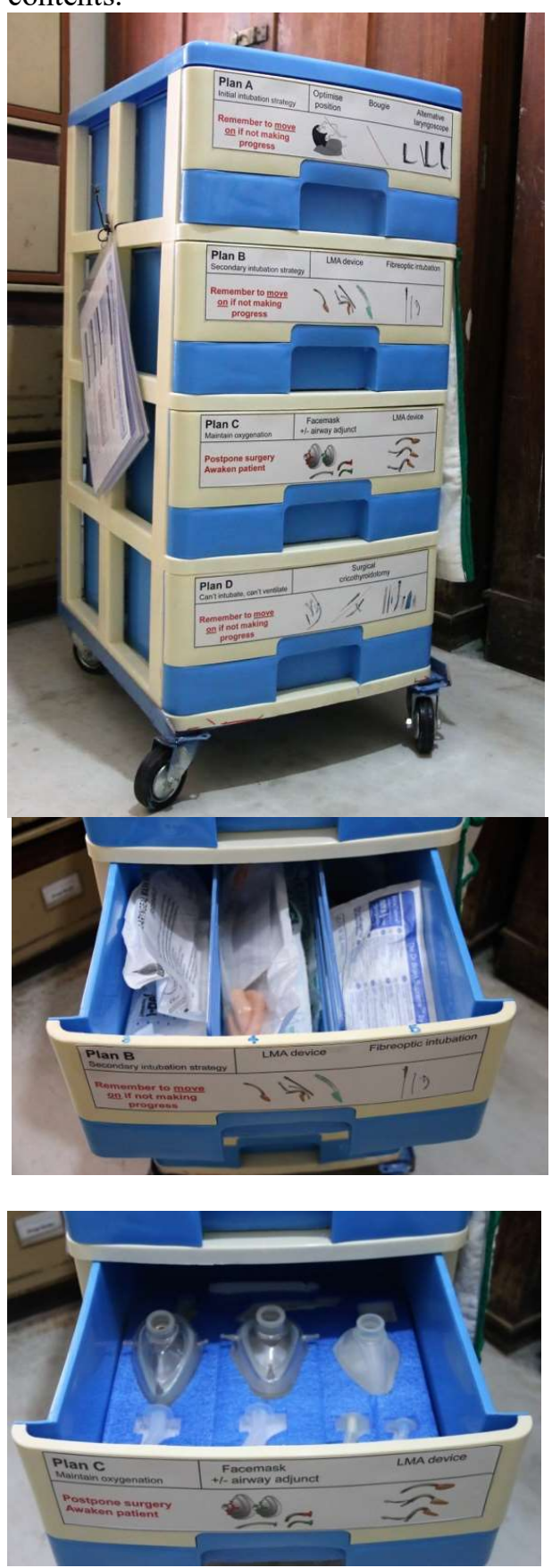
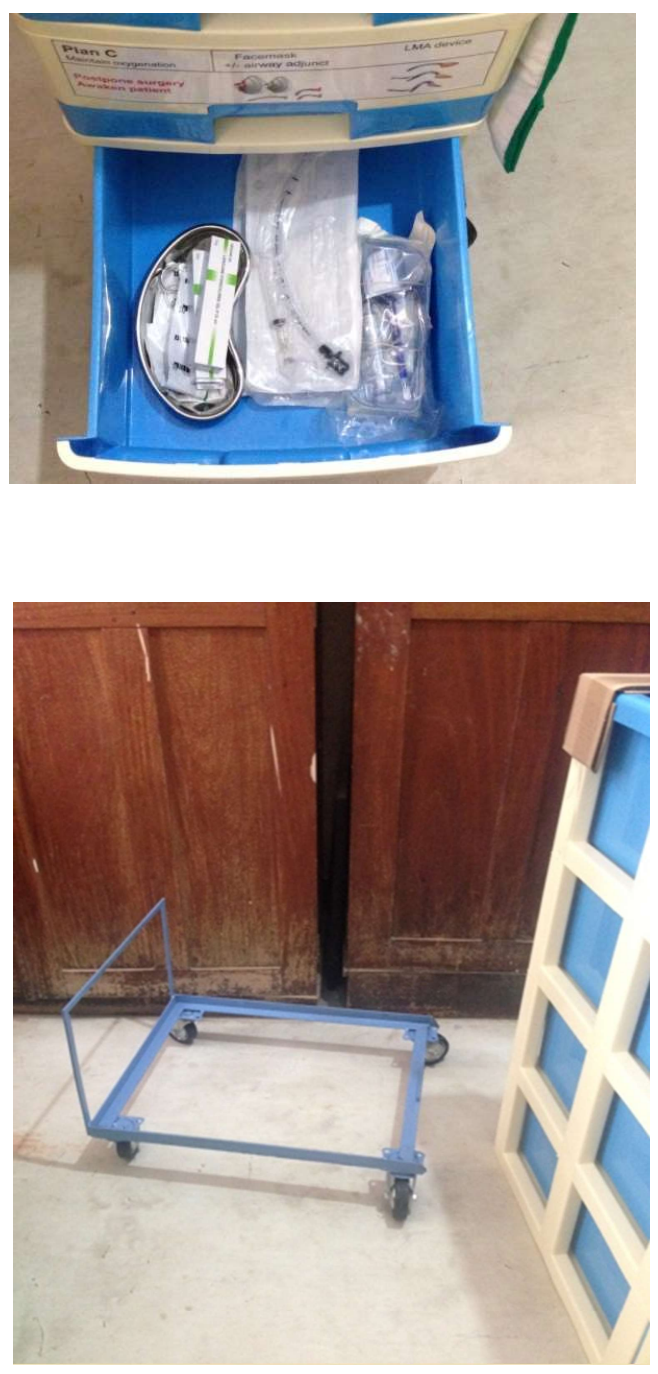

We purchased a set of plastic drawers and manufactured the frame and wheels to which it is fixed at the hospital workshop. The stickers were designed in accordance with the current DAS 2015 guidelines and the drawers were stocked accordingly.

\section{Implementation and use}

This was successfully introduced to the theatre and its personnel and it was well received. However, it is essential to ensure that they are familiar with its use. As some of the equipment is rarely used, it is vital that there is training in a comprehensive and continual manner so that in an emergency, the anaesthetists will know exactly what and where to look for and more importantly be capable of using that equipment.

\section{Further improvement}

The use of the DAT and its training should be serially audited to ensure its efficient use and 
better outcome.

We suggest this cost effective device to be used in theatres nationwide as a means of alleviating the stress of anaesthetists during difficult intubation and as a means of minimizing serious complications due to airway compromise during the management of difficult airways.

\section{References}

1. Woodall NM, Cook TM. Respiration and the Airway National census of airway management techniques used for anaesthesia in the UK: first phase of the Fourth National Audit Project at the Royal College of Anaesthetists.

https://doi.org/10.1093/bja/aeq339

2. Frerk C, Mitchell VS, McNarry AF, et al. Difficult Airway Society 2015 guidelines for management of unanticipated difficult intubation in adults. British Journal of Anaesthesia. 2015;115:827-48.

https://doi.org/10.1093/bja/aev371

PMid:26556848 PMCid:PMC4650961 